\title{
Objetos de aprendizagem para formação humanística de engenheiros de Computação
}

\author{
Thiago Veiga Santos'; David Moises Barreto dos Santos²; \\ 1. Bolsista PIBIC/CNPq, Graduando em Engenharia de Computação, Universidade Estadual de Feira de Santana, e- \\ mail: thiagoveiiga@gmail.com \\ 2. Orientador, Departamento de DEXA, Universidade Estadual de Feira de Santana, e-mail: davidmbs@gmail.com
}

PALAVRAS-CHAVE: objetivos de aprendizagem; formação humanística; engenharia de computação.

\section{INTRODUÇÃO}

Diante de temas assuntos e complexos, os objetos de aprendizagem podem ser uma alternativa para dirimir resistências e obstáculos na aprendizagem. Eles podem ser compreendidos como recursos computacionais que podem facilitar o processo de ensino-aprendizagem [Wiley, 2000]. Estes objetos podem assumir várias formas como vídeos e textos digitais, mas neste projeto daremos ênfase na produção de animações e jogos. Diante disto, este projeto visa elaborar atividades que podem ser propostas para os estudantes de TFH de formar a proporcionar o debate de temas pertinentes a este componente. Mais especificamente, pretende-se elaborar atividades didáticas a serem aplicadas no componente TFH. Tais atividades devem estimular o desenvolvimento de objetos de aprendizagem pelos próprios estudantes através do uso de Scratch. O próprio desenvolvimento de objetos de aprendizagem pelos estudantes suscitará a discussão de assuntos do referido componente. Além disso, reforçará o aprendizado técnico de programação de computadores pelo uso do Scratch, que é ferramenta lúdica para iniciantes em programação.

\section{MATERIAL E MÉTODOS OU METODOLOGIA (ou equivalente)}

A metodologia utilizada nessa pesquisa será apresentada em 3 subseções, que abrangem a população onde a pesquisa foi aplicada, os instrumentos utilizados e a análise dos dados coletados.

\section{População}

A população participante desse estudo foi composta por 25 alunos da disciplina de Tópicos de Formação Humanística - presente na grade curricular do curso de Engenharia de Computação - do semestre de 2017.1.

Dos componentes da pesquisa, 23 são do sexo masculino e 2 são do sexo feminino.

\section{Instrumento}

No contexto da disciplina supracitada, foi solicitado que os estudantes respondessem, a partir da leitura do livro "Em busca de sentido" (FRANKL, 2008), a seguinte questão (dentre outras): "O que foi mais significativo para você?". Complementarmente, foi pedido ainda que desenvolvessem um objeto de aprendizagem, ou melhor, uma animação de 1 minuto, no máximo, utilizando a ferramenta de programação educacional Scratch. Essa animação deveria estar baseada na resposta da questão mencionada.

"Em busca de sentido: um psicólogo no campo de concentração" apresenta o relato de Victor Frankl, psiquiatra austríaco que foi prisioneiro no campo de concentração de 
Auschwitz durante a segunda guerra mundial, que apesar da insuportável dificuldade vivida durante o período, buscou não tratar dos grandes horrores em demasia e sim a forma com qual os prisioneiros respondiam a inúmeros obstáculos. Os constantes questionamentos de "por que eu?" ou "qual motivo de tanto sofrimento?" eram reflexo da agonia e dor, física e mental, dos presos, porém o sonho de liberdade, a libertação interior e valorização do ser humano ajudaram Victor a perceber, que mesmo em dificuldade extrema, o ser humano poderia perceber seu sentido e razão de viver.

\section{Analise}

O processo de análise envolveu a 1) animação em si, analisando som, análise de imagem (movimentação, transição e etc), roteiro e criatividade; 2) o arquivo-fonte da animação (código-fonte em Scratch), focando na complexidade e habilidade de programação de computadores; e 3) o texto da questão supracitada, verificando não apenas o tema mencionado, usando Análise de Conteúdo (BARDIN, 2000), mas também a coerência entre este e a animação.

\section{RESULTADOS E/OU DISCUSSÃO (ou Análise e discussão dos resultados)}

Os resultados gerais da análise da animação estão na Tabela 1, onde é possível visualizar a média e o desvio padrão do estudo feito em cada critério considerado. Para cada animação foi atribuída uma pontuação de 0 a 10 critério a critério.

\begin{tabular}{l|r|r} 
& Média & Desvio Padrão \\
\hline Som & 4 & 5 \\
\hline Imagens (Presença) & 9,5 & 1,3 \\
\hline Imagens (Movimento) & 5,5 & 2,2 \\
\hline Imagens (Efeitos) & 5,8 & 1,8 \\
\hline Imagens (Transição) & 5,3 & 1,9 \\
\hline Roteiro & 6,3 & 2,5 \\
\hline Criatividade da animação & 6,4 & 1,5 \\
\hline Complexidade da lógica da programação & 6,4 & 1,7 \\
\hline Clareza da mensagem & 5,7 & 2,2 \\
\hline Coerência da mensagem com o texto (4a. Questão) & 5,3 & 2,4 \\
\hline Média total & 5,5 & 2,2 \\
\hline
\end{tabular}

Tabela 1.Média e Desvio padrão das notas atribuídas aos quesitos da pesquisa.

Os quesitos tiveram diferentes pesos e avaliaram a animação final do sujeito.

O quesito complexidade da lógica de programação foi avaliado a partir da qualidade e quantidade de blocos de funções do Scratch, que pode ser visualizado na tabela 2.

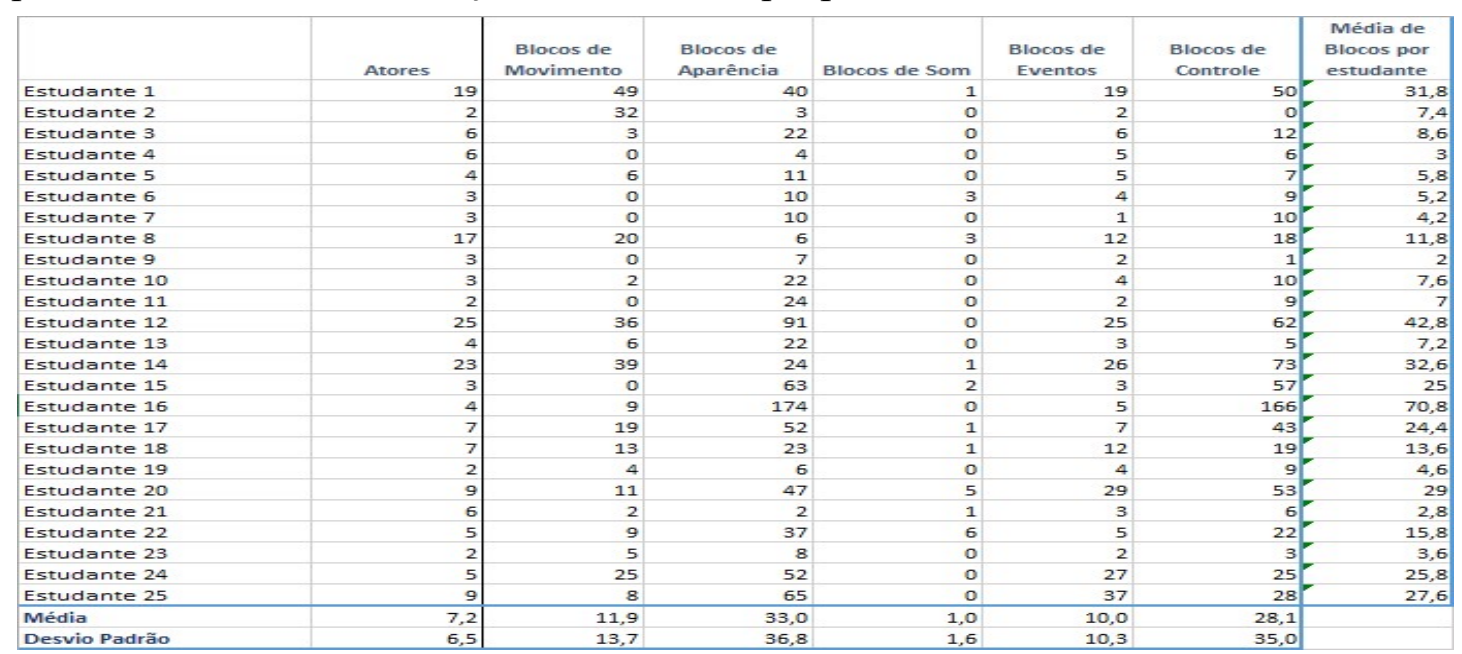

Tabela 2. Representa a média e desvio padrão de blocos de programação no Scratch 
Além de informar a média e o desvio padrão da quantidade de atores gerais, que são elementos para a construção de um programa de forma que os blocos, neles contidos, fiquem organizados, é possível visualizar média dos blocos de funções, estruturas que facilitam a relação entre as funções.

Blocos de aparência, que realizam a função de apresentar informações na tela, e blocos de controle, que por sua vez comandam a ordem das funções, são os blocos que apresentam maior média. A grande maioria dos sujeitos apresentaram esses dois blocos como suas maiores aplicações para conseguir passar a mensagem de forma clara na animação.

Os blocos de movimento são artifícios para deixar fluida a troca de imagens (frames), como visto no quesito "imagens (Movimento)". Aproximadamente metade dos colaboradores se preocuparam o suficiente com esse ponto, o reflexo é a baixa média. Já os blocos de eventos, que esperam determinados comportamentos do usuário ou do restante da aplicação tiveram uma boa média, com isso é possível perceber uma boa organização na programação dos atores.

Como dito acima, a maioria dos sujeitos não adicionaram efeitos sonoros na sua animação, isso fica mais claro ao observar a menor média dos blocos de função sendo direcionadas ao som.

A Tabela 3 apresenta os temas abordados na $4^{\text {a }}$ questão que indagava os sujeitos em relação ao que teria sido o mais significativo na experiência da leitura da obra. Apenas uma pessoa não respondeu à questão.

\begin{tabular}{|l|c|}
\hline \multicolumn{1}{|c|}{ Categoria } & Frequência absoluta \\
\hline Valor atitudinal & 17 \\
\hline Amor & 3 \\
\hline Desumanidade & 3 \\
\hline Desistência da vida & 1 \\
\hline \multicolumn{2}{|c|}{ Tabela 3. Temas da questão "O que foi mais significativo para você?" } \\
\hline
\end{tabular}

O tema mais citado é justamente a ideia mais presente no texto, de que a vida tem sentido sempre, mesmo no sofrimento. Para Frank1 (2008), isso é um valor de atitude ou valor atitudinal - e "pressupõe a capacidade humana de transformar criativamente os aspectos negativos da vida em algo positivo ou construtivo" (p. 161), ou seja, sempre extrair o melhor de cada situação. Os estudantes se surpreenderam com a capacidade de o ser humano superar situações-limite.

O segundo ponto foi o amor, especialmente, aquele retratado por Frankl pela sua esposa, como este estudante: "O que foi mais significativo para mim foi que ele conseguiu pensar na mulher dele mesmo na situação em que se encontrava". O amor pelos familiares configurou o sentido de vida de muitos prisioneiros no campo de concentração e, consequentemente, salvou muito deles. Por que continuar vivendo diante de tantas atrocidades? Pelo amor que se tinha a outras pessoas, pela esperança de ainda ter a oportunidade de amá-las se continuassem com vida. Em outras palavras, o amor tem uma força de superar desafios.

Outros três estudantes comentaram sobre a desumanização presente no campo de concentração, onde "o ímpeto da crueldade humana está em destaque", como comentou 
um estudante. As pessoas eram transformadas literalmente em objetos. Não tinham nem mais nomes, mas apenas números. Finalmente, decorrente dessa desumanização, um estudante comentou a situação de pessoas que não aguentavam tamanho sofrimento e desistiam de sua vida.

\section{CONSIDERAÇÕES FINAIS (ou Conclusão)}

A presente pesquisa buscou apoiar o estímulo da ampliação de percepção de sentido de vida, trabalhado ao longo da disciplina. Para tanto, a estratégia adotada foi o desenvolvimento de objetos de aprendizagem, através de Scratch, pelos estudantes da disciplina. A maioria deles expressou, por meio de tais objetos, uma das principais mensagens do livro: diante da dificuldade — e/ou sofrimento - , por maior que ela seja, é possível superá-la, transformando-a ou transformando a si mesmo quando ela não pode ser transformada. Este é um aprendizado extremamente importante para a vida e também para o contexto no qual os estudantes estão inseridos, especialmente, de primeiro semestre de cursos universitário, quando se deparam com mudanças e desafios significativos em suas vidas.

Infelizmente, a qualidade dos objetos de aprendizagem não foi relativamente alta. Isto pode ter acontecido por dois motivos, pelo menos. Primeiro, os estudantes, ao analisar o livro "Em busca de sentido", responderam outras questões além daquela usada como base para o objeto de aprendizagem. Portanto, isto demandou bastante tempo. A impressão é que eles se dedicaram mais na confecção do relatório do que na construção do objeto, embora tenha tido um prazo um pouco maior para a entrega. Enfim, ter estas duas atividades em paralelo pode ter dividido a dedicação às atividades. Segundo, embora Scratch seja uma ferramenta lúdica e introdutória e a grande maioria dos estudantes tenha passado por um curso desta ferramenta na primeira semana do curso, eles ainda são iniciantes em programação.

\section{REFERÊNCIAS}

WILEY, D. A. Learning Object Design and sequencing theory. Tese de doutorado. Brigham Young University. 2000. Disponível em: $<$ www.reusability.org/read/chapters/wiley.doc>. Acesso em: mar, 2016.

BARDIN, L. Análise de Conteudo. Lisboa: Edições 70, 2000.

FRANKL, V. E. Em busca de sentido: um psicólogo no campo de concentração. Petrópolis: Vozes, 2008. 